\title{
Significance of emotional intelligence for the innovative higher school teachers readiness for a person-centered interaction
}

\author{
Asya Berberyan ${ }^{1, *}$ \\ ${ }^{1}$ Russian-Armenian (Slavonic) University, Yerevan, Armenia
}

\begin{abstract}
The article examines actual problems of the strategy of the educational process in the aspect of humanization of education, which should be based on genuine self-regulation and active self-determination of the student's personality. Inthecontextof the humanistic paradigm of the educational system, an individual approach to students, encouraging the disclosure of personal potential and creative development, the possibility of emotional contact with students are investigated. The purpose of the article is to study the relationship between the innovative readiness of higher education teachers and emotional intelligence. The methodological basis of the research are the works of such researchers in the field of a personalitycentered approach to education as K. Rogers, I.V. Abakumova, I.S. Yakimanskaya, V.V. Serikov, E.V. Bondarevskaya, M.A., Andreev V.I. and others, as well as conceptual provisions in the field of emotional intelligence of scientists (J. Meyer, P. Salovey and D. Caruso R. Bar-On and D. Goleman N. Hall).We have chosen as research methods: diagnostics of "emotional intelligence" (N.Hall); questionnaire to identify the level of innovative readiness for personality-centered interaction of university teachers (author's methodology). As a result of the conducted empirical research, the hypothesis put forward by us about the presence of a positive correlation between emotional intelligence and the innovative indicator of the ability for person-centered interaction of higher school teachers was confirmed.
\end{abstract}

\section{Introduction}

Humanistic psychology defines key guidelines for finding answers to numerous questions relevant to the modern education system. Theseare, firstof all, the issues of humanistic innovations in the field of education, personal development of students, conditions for achieving the maximum humanistic effect. Non-role, humanized communication for both students and teachers in the field of higher education carries great prospects. This is a new type of awareness of oneself and others $[2,4,13]$. The social institution of education plays such an important and key role in the life of society that it is able to ensure its cultural, moral the educational process into a humanely oriented process through the implementation of the basic principles of humanism in it. A complete learning process is based on personality. According to K. Rogers, the main task of the teacher is to stimulate, or facilitate, meaningful

\footnotetext{
* Corresponding author: aspsy@inbox.ru
} 
learning, which is learning, freely and independently initiated by the student himself. Such a system is considered by $\mathrm{K}$. Rogers as a real reform of education, based not on the development and implementation of new experimental programs in the learning process, improvement of knowledge, skills and abilities, but on the restructuring of certain personal attitudes of the teacher, implemented in the processes of his interpersonal interaction with students [25].

At the present stage of development of society, the process of humanization of education is gaining more and more relevance and importance, and the classical image of a "conservative" teacher, who set as his exclusive goal the transfer of knowledge and information enrichment of students, without attaching importance to the emotional component of the learning process, has actually lost its significance.

The educational system becomes that social institution that not only conducts knowledge training, but also contributes to the formation of motives for self-development, the acquisition of the need for self-realization, the formation of an independent personality capable of selfdetermination, self-development, self-position, stimulates the intention to search for and reveal personal meanings, the formation of a humane and existent a person capable of designing his own life, living "here and now," and ultimately determining the sustainable development of society. Inthelastdecade of active reforming of the education system in Armenia, there has been a restructuring of the traditional education system, the desire to humanize education. The traditional education system leads to the fact that the subject of the educational process with theoretical training is not ready for the practical development of professional activity. The strategy of the educational process in the context of the humanization of education should be based on genuine self-regulation and active selfdetermination of the student's personality. The concept of humanization of the educational system is aimed at creating conditions for the self-development of the individual; humanistic psychology prohibits any direct impact on the individual, since artificial limitation of freedom of choice, independent development of the personality inhibits the development of creative, creative capabilities of the individual" [2, 3, 14].

Since the teaching process from the standpoint of the humanistic paradigm of education is an interpersonal subject-subject interaction, consideration of the role and meaning of emotional intelligence is associated with the person's ability to recognize emotions, understand the emotions of other people, their motivation, as well as the ability to control not only their own, but also their emotions other people to solve practical problems [20,21,22,24].

Based on the above definition, we can conclude that the presence of a high EQ (emotional intelligence) for a teacher is necessary, especially in the context of the humanization of education, since establishing emotional contact with students, an individual approach to students, encouraging the disclosure of personal potential and creative development of students lead to better and more meaningful assimilation of knowledge and skills provided by the educational system.

\section{Materials and methods}

The general hypothesis of the study is the assumption that there is a positive correlation between innovative readiness for person-centered interaction and a high indicator of emotional intelligence of higher education teachers.

Thepurposeofthe article is to study the relationship between the innovative readiness of higher education teachersandemotionalintelligence. 


\section{Theoretical and methodological foundations}

The methodological basis of the research is the work of such researchers in the field of a personality-centered approach to education as K. Rogers, I.V. Abakumova, I.S. Yakimanskaya, V.V. Serikov, E.V. Bondarevskaya, M.A., Andreev V.I. etc., and as well as conceptual provisions in the field of emotional intelligence of scientists (J. Meyer, P. Salovey and D. Caruso R. Bar-On and D. Goleman N. Hall).

Research methods are: questioning, testing. We have chosen as research methods:

1. Diagnostics of "emotional intelligence" (N. Hall);

2. Questionnaire to identify the level of innovative readiness for personality-centered interaction of university teachers (author's methodology).

The new model of education considers personality-centered upbringing and education as the leading idea of pedagogical theory and practice (Abakumova I.V., Bondarevskaya E.V., Rogers K., Serikov V.V., Yakimanskaya I.S., etc.).

There is no common understanding of the personality-oriented approach in modern education, despite the fact that it occupies a leading position today.

At the heart of the concept of sense-centrism: (strategies of sense formation and semantic regulation) are reflexive centralizations of the personality as various semantic neoplasms as a determining factor in the process of students' variable choice and provide internal differentiation in the educational process. In the center of conceptual construction, the personal, deep, semantic aspects of education and training are displayed. The authors of this concept are I.V. Abakumova, P.N. Ermakov. $(2003,2006)$ - convincingly showed that if the educational process is built according to the way students reveal the meaning of the objects, events, concepts being studied, this would make education more effective, effectively influencing the life and spiritual values of the forming personality, which helps to bridge the gap between the gnostic and personal in the educational process [1].

The positional didactic concept underlies the model of personality-oriented education proposed by V.V. Serikov. [9]. He believes that it is necessary to provide conditions for personal growth, the development of the ability for strategic activity, criticality, creativity, sense-making, the ability of an individual to self-determination, self-development, a positive self-concept, etc.

E.V. Bondarevskaya proposed a culturological model of personality-centered education [5]. This model provides personal and semantic development of students. The main idea of its concept is that the development of a student is considered not only as a subject of life, a subject of knowledge, but also as a subject of culture - its bearer, keeper, user, creator. Speaking about personality-centered education, we mean not only the individual psychological characteristics of students, but also a certain type of organization of the educational process, which is based on the interaction between teacher and student. This type creates more suitable conditions for the development of students' abilities for self-education and the implementation of their creative abilities.

Yakimanskaya I.S. several conditions for the psychological and pedagogical implementation of personality-centered learning were identified, which consist in the development of subject content and technology for its use; in the analysis of the use by students of various ways of working out educational material; in the focus of a person's interests and abilities, in accordance with this - drawing up an individual development map, and then an individual correctional training program, based on success in achievement; and the construction of the lesson should be based on the creation of conditions for selfrealization, independence, the use of active forms of communication (monologue, dialogue, etc.) was especially encouraged [11] The above means that the issue of selection of the content of personality-centered education is quite acute. Suchtrainingshouldinclude 
everything necessary for the construction and development of the personality of the growing person.

It is worth recognizing that the personality component in the content of the personalitycentered approach to education is system-forming (this is precisely what it differs from the traditional one, where the cognitive component is recognized as such). The peculiarity of the embodiment of the process of personality-centered education lies in the creation of a certain pedagogical situation, which confronts the student with the need to prove himself as a person, such a personality-oriented situation is called a "demand situation", which "launches the mechanisms" of personal growth, it addresses the issues of self-determination, recognition , status, leading vital needs. The creation of such a situation allows the use of three fundamental technologies: understanding the elements of the content of education as multilevel personality-oriented tasks; assimilation of the content within the framework of the dialogue as a certain didactic and communicative environment that provides subject-semantic communication, self-realization of the personality, reflection; imitation of spatio-temporal and social-role conditions that could ensure the implementation of personal functions in conditions of internal conflict.

Person-centered learning emerged as an alternative to traditional "cognitive-centered" learning. Today it is facing serious difficulties, for example, in pedagogy there is no unified approach to building a model of personality-centered education; already existing developments are difficult to implement in practice, because they do not give clear guidelines for implementation. That is why we can talk about the multiplicity of concepts of a personality-oriented approach to education.

The main feature of a humanely oriented educational process is the modification of its structure, functions and driving forces: education forms a person's individuality, his formation; the teacher's attitude to the student is changing; the personal component, in the content of the educational process, becomes system-forming. Changing the organization of the teaching process will make it possible to include the student in the learning process and fully develop it. Thus, the organization of the teaching process, based on the principles of a humane and personal approach, activates the activities of both teachers (choosing the optimal teaching aids, their methods and forms) and students (meeting their needs), which will increase the quality of educational services and the quality of education. people in general.

The humanization of education is a humane attitude towards a student, the ability to discern a personality in him and accept him as he is, a reflection of his individuality and uniqueness, as well as the ability to develop the inclinations given to him by nature [10]. Personality potential in modern scientific literature is defined as a synthesis of personality traits that reveal the intellectual, creative and motivational potential. determining the possibility of high achievements in the personal and professional spheres [8].

General cultural values of education make it possible to understand the value of the teacher's personality as a subject of culture, capable of creativity, self-improvement, selftransformation to solve the problems of increasingly complex creative teaching activities, the development and manifestation of relationships, a system of meanings, spirituality, morality, humanity.

The term "emotional intelligence" appeared at the end of the 20th century. foreign psychology. Emotional intelligence was originally understood as the ability to process information contained in emotions, to determine the meaning of emotions, their relationship with each other, and the use of emotional information as a basis for thinking and decisionmaking. In recent years, a large number of studies have been carried out aimed at analyzing and finalizing the definition of the concept of emotional intelligence, as well as creating the most complete model of this construct. The problem of competence in understanding and expressing emotions is quite acute in our society, since the cult of a rational attitude to life is 
gaining an increasing number of supporters, it is, in principle, a contradiction to psychophysiological, social characteristics and human needs.

Based on this concept, J. Meyer, P. Salovey and D. Caruso created the concept of emotional intelligence, and later, the first model was compiled. The very first version of this model was proposed in 1990. The authors defined "emotional intelligence" as the ability to identify both one's own emotions and those of others, and to use this information to make decisions. Thus, "emotional intelligence" was presented as a construct, consisting of the following abilities: 1) the ability to identify and express emotions; 2) the ability to regulate emotions; 3 ) the ability to use emotional information in thinking and acting. According to the authors, each of these types of abilities has a number of components. Later, P. Salovey and J. Mayer finalized the described model and determined four components that make up the structure of emotional intelligence. These components are arranged in a kind of hierarchy, the levels of which, according to the authors' assumption, are consistently mastered in ontogenesis. $[16,17]$. So the components:

- Identification of emotions. The component includes a number of interrelated abilities, which are the perception of emotions, adequate expression, their identification, discrimination of true emotions or their imitation.

- Using the features of emotion in order to increase the efficiency of thinking and activity. The component includes the ability to use emotions to focus attention specifically on important events, as well as the ability to evoke emotions that contribute to solving problems, such as using a good mood to generate creative ideas; it also includes using mood swings as a good tool for analyzing different perspectives on a problem.

- Understanding emotions. It means the ability to understand a complex of emotions, interemotional connections, causes of emotions, transitions from one emotion to another, verbal information about emotions.

Emotion management. It means the ability to control emotions, reduce the effect of negative emotions, understanding and awareness of their emotions, positive and negative, the ability to solve emotional problems without suppressing negative emotions associated with them. Emotion management promotes personal growth and better interpersonal relationships.

In parallel, in the 1990s.other models have emerged that represent a slightly different view of emotional intelligence. the models of R. Bar-On and D. Goleman are the most famous of them.

In 1988, Ruven Bar-On defined the concept of emotional and social intelligence and put forward the assumption that it consists of many, both deeply personal and interpersonal abilities, skills and abilities, the combination of which determines human behavior. Also, Bar-On first introduced the designation EQ - emotionalquotient, the coefficient of emotionality, drawing an analogy with IQ - the coefficient of intelligence [6, 12].

In 1995, D. Goleman changed and popularized the first model of emotional intelligence, Meyer J. and Salovey. P. Goleman added a few more components to the components they highlighted, like persistence, enthusiasm and social skills. Thus, he combined the cognitive abilities that were part of the Salovey and Mayer model with personality characteristics. [15]. A clear merit of D. Goleman is the call of people to develop personal qualities that contribute to the achievement of success in various fields of activity. Obviously, the structural components of emotional intelligence that Goleman identifies include not only emotional abilities, but also volitional qualities, social skills, and characteristics of self-awareness.

A fundamentally new model of emotional intelligence was proposed in 2004 by the Russian psychologist Lyusin D.V. The author defines emotional intelligence as the ability to understand one's own and other people's emotions, as well as the ability to control them [7]. In fact, the concept of EQ emphasizes the relationship between the affective and cognitive spheres of the psyche, accompanying the successful resolution of life tasks. However, the views of researchers on the interaction of emotional and cognitive processes were not always 
unambiguous and changed over time. Emotional intelligence in a broad sense is the recognition of both positive and negative feelings for oneself and others, the ability to separate personal feelings from bare facts, as well as the skill to feel mood, temperament, intonations and intentions in communicating with other people, regardless of whether they are old acquaintances or you see them for the first time in your life. An important part of emotional intelligence is the ability to recognize and honestly describe one's own emotions, the ability not to panic and reject "bad emotions" (anger, jealousy, irritation, envy, anger) and the widespread use of emotionally colored language with self-messages [18.19.23].

\section{Results}

We conducted a study with teachers from various universities in Armenia. Thetotalnumberof respondents was 36 people.

1. The test of "emotional intelligence" by N. Hall is intended to identify the ability to understand the personality's relations represented in emotions, as well as to study the possibility of managing one's own emotional sphere on the basis of decisions made.

2. The questionnaire for identifying the level of innovative readiness for person-centered interaction of university teachers (author's methodology) is designed to determine the typological characteristics of teachers based on their attitude to the field of innovation and innovative changes.

The data obtained using the N. Hall method for diagnosing emotional intelligence are reflected in the following table 1:

Table 1.The results of diagnostics of emotional intelligence by means of N. Hall's method.

\begin{tabular}{|l|c|c|c|}
\hline & High & Medium & Low \\
\hline Scale "Emotionalawareness" & $52 \%$ & $34 \%$ & $14 \%$ \\
\hline Scale "Managingyouremotions" & $49 \%$ & $32 \%$ & $19 \%$ \\
\hline Scale "Self-motivation" & $43.5 \%$ & $40.5 \%$ & $16 \%$ \\
\hline Empathyscale & $74.5 \%$ & $18 \%$ & $7.5 \%$ \\
\hline Scale "Managing other people's emotions" & $51 \%$ & $36 \%$ & $13 \%$ \\
\hline
\end{tabular}

After analyzing the data obtained to identify the prevailing integrative indicator of the level of emotional intelligence, the following result was obtained: the largest number of respondents have a high integrative level of EQ - (64.5\%), 27\% - an average level of EQ, finally $8.5 \%$ - a low integrative indicator EQ.

2) Accordingtothe results of the author's methodology for identifying the level of innovative readiness for person-centered interaction, we received data.A positive conceptualmethodological and technological indicator of the ability for person-centered interaction is the indicators of innovation, enthusiasm and rationalism amonghigherschoolteachers.

\section{Conclusion}

The hypothesis suggesting a relationship between emotional intelligence and typological characteristics of innovative readiness for person-centered interaction was partially confirmed, since the study found an average correlation equal to 0.64539211 .

However, among respondents with a high level of integrative EQ (29 respondents out of $36-80.5 \%$ ), the largest number of subjects have such types of innovative readiness for learning as an innovator (10 subjects out of 29 - 35\%) and an enthusiast ( 7 subjects out of 29 - $24 \%$ ), which indicates a complete confirmation of our hypothesis about the presence of a 
positive correlation between emotional intelligence and the innovative indicator of the ability for personality-centered interaction of higher school teachers.

In our opinion, the key role in the development of modern society is facilitated by the readiness for person-centered interaction, which underlies the student's creative development and his potential, as well as indicators of the teacher's humanistic orientation.

\section{References}

1. I.V. Abakumova, P.N. Yermakov, I.A. Rudakova, Smyslotsentrizm v pedagogike (Rostov-on-Don, 2006)

2. A.S. Berberyan, Psikhologiya vysshego obrazovaniya v kontekste gumanizatsii: uchebnoye posobiye (Vedeckovydavatelske centrum «Sociosfera-CZ», Praga, 2014)

3. A.S. Berberyan, Vestnik-Mezhdunarodnoya kademii nauk ekologii I bezopasnosti zhiznedeyatel'nosti 14(4), 23-26 (2009)

4. A.S. Berberyan, E.S. Berberyan, O.R. Tuchina, Psikhologicheskiy zhurnal, Rossiyskaya akademiya nauk 2 (2019)

5. Ye.V. Bondarevskaya, Teoriya I praktika lichnostno-oriyenti-rovannogo obrazovaniya (Rostov-on-Don, 2000)

6. D. Goulman, Emotsional'nyyintellect (AST, Moscow, 2008)

7. D.V. Lyusin, Sposobnost' kponimaniyuemotsiy: Psikhometricheskiy I kognitivnyy aspekty (Moscow, 2000)

8. K. Rodzhers, K nauke o lichnosti. Istoriya zarubezhnoy psikhologii (Teksty, Moscow, 1986)

9. A.I. Savenkov, Odarennyy rebenok 6, 22-36 (2007)

10. V.V. Serikov, Lichnostnyypodkhod v obrazovanii: kontseptsiiitekhnologii (Volgograd, 1994)

11. I.A. Shcherbakova, Conference 2013 Lichnost', sem'yaiobshchestvo: voprosypedagogikiipsikhologii: sb. st.po mater. XXV mezhdunar.nauch.-prakt. konf. (SibAK, Novosibirsk, 2013)

12. I.S. Yakimanskaya, Personality-oriented education technology (Moscow, 2000)

13. A.S. Berberyan, H.S. Berberyan, Comparative analysis. Psychology in Russia: State of the Art 9(1), 121-137 (2016) DOI: 10.11621/pir.2016.0109

14. A.S. Berberyan, R. Gabrielyan, International Conference "Entrepreneurial and Sustainable Academic Leadership” (ESAL2018) (Prague Institute for Qualification Enhancement (PRIZK), 2018) https://link.springer.com/book/10.1007\%2F978-3-03015495-0

15. R. Bar-On, Emotional intelligence in everyday life: a scientific inquiry (Psychology Press, New York, 2001)

16. D. Goleman, Working with emotional intelligence (New York, Bantam B, 1998)

17. D.R. Caruso, P. Salovey, Emotion Review 1, 11 (2016) DOI: $10.1177 / 1754073916639667$

18. K. Cherry, 5 Components of emotional intelligence. Very Well Mind (2018) https://www.verywellmind.com/components-of-emotional-intelligence-2795438

19. I. Faltas, Three models of emotional intelligence (2017) https://www.researchgate.net/publication/314213508_Three_Models_of_Emotional_In telligence/download 
20. P. Fernández-Berrocal, N. Extremera, Emotion Review 8(4), 311-315 (2016)

21. J.D. Mayer, Emotional intelligence in everyday life (Philadelphia, P.A., 2001)

22. J.D. Mayer, D.R. Caruso, P. Salovey, Emotion Review 8, 290-300 (2016) doi: $10.1177 / 1754073916639667$

23. M. Meshkat, R. Nejati, A study on undergraduate English majors of three Iranian universities (2017) https://doi.org/10.1177/2158244017725796

24. C. Miao, R.H. Humphrey, S. Qian, J. Occupat. Organiz. Psychol. 90, 177-202 (2017) doi: 10.1111 joop. 12167

25. C.R. Rogers, On Becoming a Person (Houghton Miffl in Boston, 1961) 